\title{
Healthcare-Associated Infection in Developing Countries: Simple Solutions to Meet Complex Challenges
}

\author{
Benedetta Allegranzi, MD; Didier Pittet, MD, MS
}

Healthcare-associated infections are usually linked to sophisticated medical technology and the use of invasive devices. Their potential impact on patient safety in developing countries is, therefore, perceived as incidental. Furthermore, in countries with an annual per capita income less than US $\$ 2,000$ and where less than $5 \%$ of the gross national product is spent for health, infection control may be considered a luxury that uses resources needed for other very pressing health priorities. ${ }^{1}$ Available data seem to clearly demonstrate that this point of view is distorted and subject to bias.

In developing countries, the unsafe use of injection equipment, other medical devices, and blood products; inadequate surgical procedures; and deficient biomedical waste management result in thousands of infections acquired not only from patients, but also from healthcare workers-most of them unreported. The World Health Organization (WHO) estimates that the proportion of injections given with syringes or needles that are reused without sterilization is between $1.5 \%$ and $69.4 \%$ in transitional and developing countries. ${ }^{2}$ In a survey conducted in 22 developing countries, the percentage of facilities not using proper waste disposal methods ranged from $18 \%$ to $64 \% .^{2}$ Furthermore, in $2000-2001$, the WHO announced the alarming fact that more than 70 countries did not test all donated blood for human immunodeficiency virus, hepatitis $B$, hepatitis $C$, and syphilis. As a consequence, unsafe blood transfusions and injections result in an astounding number of new infections due to hepatitis B virus, hepatitis $C$ virus, and human immunodeficiency virus every year (Table). ${ }^{2,3}$

In industrialized countries, healthcare-associated infection is a complication for between $5 \%$ and $10 \%$ of patients admitted to acute care hospitals. In developing countries, the risk of infection is 2-20 times higher, and the proportion of patients infected can exceed $25 \% .^{4-8}$ In a recent study in intensive care units (ICUs) in 8 developing countries, the overall device-associated infection rates were as high as 22.5 cases per 1,000 ICU-days, and the rates of specific device-associated infections exceeded by several times those reported in in- dustrialized countries. ${ }^{9}$ Similarly, the rates of bloodstream infection in neonates are 3-20 times higher in developing countries, and, in some countries, approximately half of the patients in neonatal ICUs acquire an infection, and case fatality rates may reach $52 \% .{ }^{10}$ In developed countries, between $2 \%$ and $5 \%$ of patients who undergo surgery develop a surgical site infection; in developing countries, much higher rates are reported, ranging from $12 \%$ to $39 \%$, $^{2,11}$

A complex range of factors determines the risk of acquiring an infection in healthcare settings in developing countries. The view that antimicrobial resistance substantially facilitates the spread of nosocomial pathogens is well known. In developing countries, inappropriate use of antibiotics and the use of counterfeit drugs contribute to very high resistance rates, although this is poorly documented because of the lack of reliable surveillance systems. In a report on neonatal ICUacquired infections in different countries, $36 \%$ of Staphylococcus aureus isolates recovered were reported to be methicillin-resistant strains (MRSA), and $46 \%$ of Escherichia coli strains and $51 \%$ of Klebsiella species strains were resistant to third-generation cephalosporins. ${ }^{10}$ In adult ICU patients, MRSA accounted for $84 \%$ of healthcare-associated infections, and third-generation cephalosporin-resistant Enterobacteriaceae accounted for $51 \% .^{9}$

Understaffing and low levels of staff preparedness and knowledge are key factors leading to poor infection control in developing countries. The WHO Health Report 2006 revealed that worldwide, 57 countries (all developing) currently have critical staff shortages, equivalent to a global deficit of 2.4 million physicians, nurses, and midwives. ${ }^{12}$ Given this situation, the education and recruitment of infection control professionals is very far from being a realistic solution. Governments struggling with other well-known health priorities clearly are not primarily committed to developing infection control policies and standards. Several factors make the implementation of minimum standards for infection control very difficult, including poor hygiene and sanitation; lack or shortage of basic equipment, such as gloves; inadequate struc-

From the World Alliance for Patient Safety, World Health Organization Headquarters (B.A.), and Infection Control Programme, University of Geneva Hospitals, Geneva, Switzerland (B.A., D.P.).

Received June 11, 2007; accepted July 11, 2007; electronically published October 22, 2007.

Infect Control Hosp Epidemiol 2007; 28:1323-1327

(C) 2007 by The Society for Healthcare Epidemiology of America. All rights reserved. 0899-823X/2007/2812-0002\$15.00. DOI: 10.1086/521656 
TABLE Estimated Worldwide Number of Infections Caused Each Year by Unsafe Injection and Blood Transfusion Practices

\begin{tabular}{lcc}
\hline Type of infection & $\begin{array}{c}\text { Cases due to } \\
\text { unsafe injection }\end{array}$ & $\begin{array}{c}\text { Cases due to } \\
\text { unsafe transfusion }\end{array}$ \\
\hline Hepatitis B virus & $21,000,000$ & $16,000,000$ \\
Hepatitis C virus & $2,000,000$ & $5,000,000$ \\
HIV & 260,000 & 160,000 \\
\hline
\end{tabular}

Note. Estimates adapted from the World Health Organization Global Patient Safety Challenge ${ }^{2}$ and a report in The Lancet. ${ }^{3}$ HIV, human immunodeficiency virus.

tures and overcrowding; and limited availability of surveillance data. In addition to these specific factors, a population widely affected by malnutrition and endemic infection contributes to the increased risk of healthcare-associated infection in developing countries. Despite this discouraging picture, simple and applicable prevention measures and tools do exist. Their effectiveness has mostly been demonstrated in settings with adequate resources but remarkable examples of the implementation of interventions to reduce healthcareassociated infection are also available from studies conducted in developing countries. ${ }^{13-18}$

A global response to the problem of healthcare-associated infection has been recently initiated by the WHO World Alliance for Patient Safety. Given the critical nature of this health problem, the project was launched as the First Global Patient Safety Challenge, "Clean Care is Safer Care." ${ }^{\text {2,19 }}$ It aims at reducing healthcare-associated infection worldwide by strengthening integrated actions in the areas of blood safety, injection safety, and clinical procedure safety, as well as water, sanitation, and waste management safety. The cornerstone of the entire initiative focuses on the promotion of hand hygiene in health care. The objectives of "Clean Care is Safer Care" will be achieved through 3 key efforts: (1) efforts to increase global awareness of healthcare-associated infection as a major issue threatening the safety of patients and healthcare workers, (2) efforts to catalyze countries' commitment to make progress in this field, and (3) efforts to identify and test sound recommendations and strategies to implement basic infection control interventions in healthcare settings worldwide.

During the first 18 months of the First Global Patient Safety Challenge, ministries of health from 43 countries signed a formal statement pledging to reduce healthcare-associated infection; 22 of these 43 are developing countries. At least 20 additional countries have planned to pledge by the end of 2007; combined, this would represent $75 \%$ of the world's population. After making the pledge, several countries from the developing world, including Bahrain, Costa Rica, Iran, Malaysia, and Mali, have documented progress, such as the development of new infection control policies, the allocation of funds and human resources to infection control, the inauguration of training programs and surveillance systems, preparation of national guidelines, and actual implementation of interventions in healthcare settings.

From rural dispensaries in developing countries to the most technologically-advanced tertiary care centers in the developed world, the lack of compliance with hand hygiene in healthcare settings remains problematic, despite the fact that hand hygiene is a simple, highly effective measure for reducing the rate of healthcare-associated infection and the spread of antimicrobial resistance. ${ }^{20,21}$ The technical work of the First Global Patient Safety Challenge has addressed this issue by focusing on the improvement of hand hygiene in healthcare settings worldwide. To provide healthcare workers,

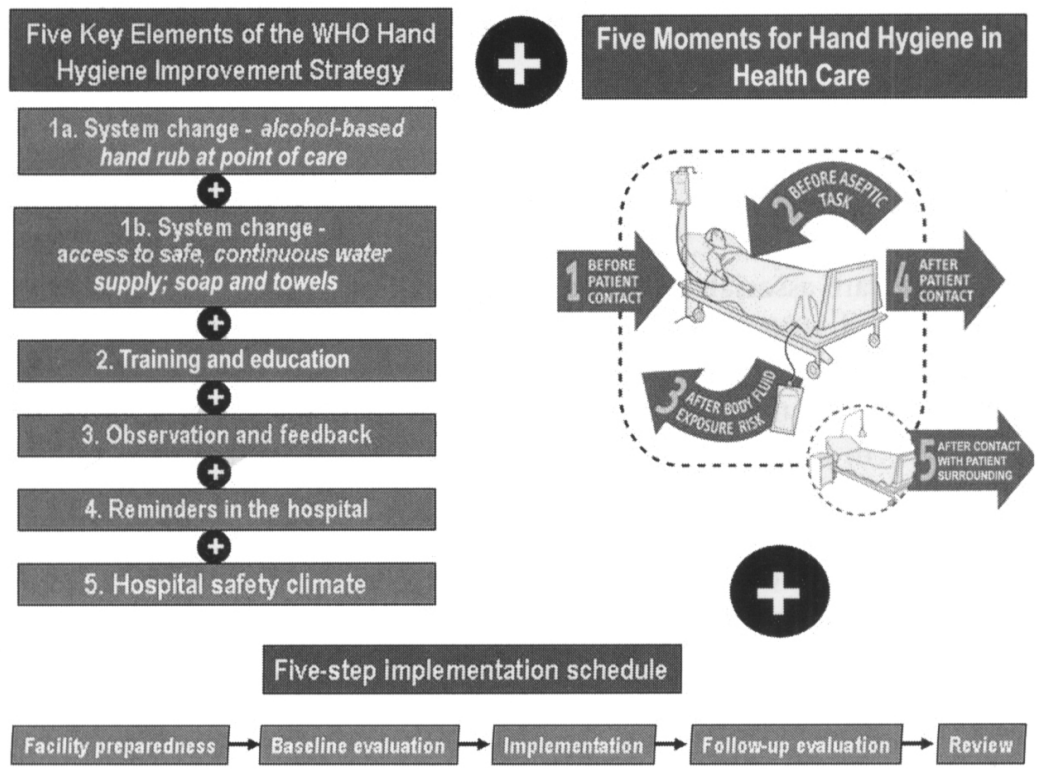

FIGURE 1. The World Health Organization (WHO) multimodal implementation strategy to improve hand hygiene in healthcare settings. 


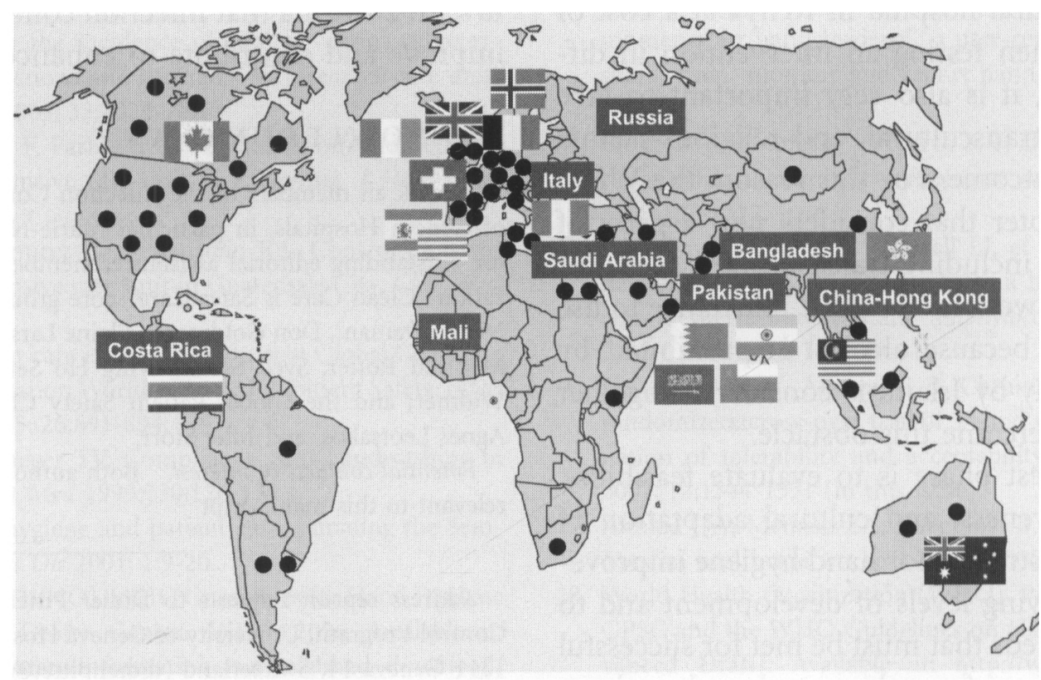

FIGURE 2. Countries testing the World Health Organization multimodal implementation strategy to improve hand hygiene as of September 2007. Rectangles, pilot sites; circles, complementary sites; flags, countries where a national or regional hand hygiene campaign is ongoing.

hospital managers, and health authorities with the best evidence and recommendations to improve practices, the WHO has put together the best scientific evidence available and drawn on expertise from more than 100 renowned international experts and experienced clinical professionals to develop the new "Guidelines on Hand Hygiene in Health Care (Advanced Draft)." ${ }^{22}$ This worldwide movement, catalyzed by the First Global Patient Safety Challenge, includes some 15 countries that have already launched national or regional hand hygiene promotion campaigns, all of which refer to the WHO guidelines.

A multimodal implementation strategy (Figure 1) has been developed to turn the scientific evidence included in the WHO guidelines into practice and to suggest feasible ways to induce changes that will ultimately result in increased hand hygiene compliance and reduced morbidity and mortality due to healthcare-associated infection. To enable any healthcare setting to easily start a hand hygiene improvement campaign, the proposed strategy includes 5 key elements based on scientific evidence that are considered to be essential minimum requirements for improving hand hygiene. The strategy is suitable for both developed and developing countries. Depending on local resources and culture, additional actions might be included, for example, patient involvement.

An implementation pack of practical tools is available to healthcare facilities to help with step-by-step implementation of all 5 key elements of the strategy. The tools address the following target areas: operation, advocacy and information; education; monitoring; hand hygiene product procurement; and impact evaluation. To make a real change, the indications for hand hygiene should be universally understandable and no longer open to interpretation. An innovative approach is proposed, therefore, which focuses on only 5 points in time when hand hygiene is required ${ }^{23}$ while providing health care and which aims at integrating the indications easily into the work flow (Figure 1).

One of the key evidence-based changes that promote successful hand hygiene is the systematic switch to alcohol-based hand rub at the point of care as the "gold standard" practice. ${ }^{24,25}$ To increase hand hygiene compliance worldwide, the WHO recommends making the use of alcohol-based hand rubs preferable to hand washing in most situations. ${ }^{22} \mathrm{Un}$ fortunately, products already on the market are of varying quality and efficacy and are far too costly for healthcare settings that have limited resources. To overcome this obstacle, 2 hand rub formulations with proven microbiological efficacy and a good safety profile were identified by international experts that can be produced easily at the facility level. A "Guide to Local Production" is now available, which features simple instructions and illustrations detailing the process from procurement of raw ingredients to quality control and storage of the final product. Product tolerability and acceptability have been tested and are remarkable. ${ }^{22,26}$

A worldwide pilot test of the strategy and tools is currently ongoing in a large number of healthcare settings in developed and developing countries (Figure 2). As shown, though less than 2 years have passed since the launch of the First Global Patient Safety Challenge, interventions to promote hand hygiene at the national or regional level are currently ongoing in at least 15 countries; there are also ongoing interventions at the level of the healthcare setting in an additional 18 countries. Several facilities from developing countries are participating, and some (Costa Rica, Egypt, Kenya, Mali, and Mongolia) have already successfully implemented local production of the WHO-recommended alcohol-based formulations. As an example, the entire process of producing the WHO-recommended ethanol-based formulation, from the procurement of raw ingredients to distribution, has been shown to 
be feasible in a remote, rural hospital in Kenya at a cost of US\$0.37 per $100 \mathrm{~mL}$. When testing an intervention in different settings worldwide, it is also very important to take into account behavioral, transcultural, and religious factors that may influence the outcome. For this reason, the WHO Guidelines include a chapter that considers new aspects of hand hygiene promotion, including transcultural issues. For instance, some healthcare workers' possible reluctance to use alcohol-based hand rubs because alcohol is prohibited by some religions, particularly by Islam, is considered together with potential ways to overcome this obstacle. ${ }^{27}$

The aim of the pilot test phase is to evaluate feasibility, sustainability, cost-effectiveness, and cultural adaptation of the proposed multimodal strategy for hand hygiene improvement in settings with varying levels of development and to learn about the cultural needs that must be met for successful adaptation. Once the findings from the test phase have been collected and analyzed, the WHO Guidelines and the implementation strategy will be finalized. This approach has been judged to be an exemplar for WHO guideline preparation and, in particular, the implementation strategy may be used as a model for future interventions. Facilities that are interested in using the WHO multimodal strategy for hand hygiene improvement can register as complementary sites and access the tools freely via the Internet ${ }^{28}$; facilities that use the strategy are subsequently asked to share their experience and findings.

Healthcare-associated infection has all the peculiar characteristics of being a major patient safety problem from which no hospital, no healthcare system, and no country in the world can claim to be exempt. In developing countries, until recently the issues related to healthcare-associated infection were only considered in relation to epidemic events-that is, as part of a threatening health concern that required urgent attention. If insufficient infection control practices are in place, endemic transmission of harmful pathogens to patients and staff members ensues during the delivery of health care. Therefore, the lack of knowledge and the way that the problem is perceived are the basic determinants of the rate of healthcare-associated infection in developing countries, together with the adequacy of structures and equipment.

The First Global Patient Safety Challenge represents an unprecedented initiative to improve infection control practices and procedures in any healthcare setting, regardless of the level of economic development. Never before in the history of infection control has there been such an opportunity to improve the health of so many millions of individuals by promoting basic but essential practices through the powerful channels of the WHO, which allow the involvement of governments and influence their healthcare systems. The large number of countries that have already pledged to address healthcare-associated infection in only 18 months testifies to the desire for change on each continent. Results obtained from worldwide testing will be invaluable in helping to shape scale-up and sustainability worldwide and will go a long way toward ensuring that infection control practices continuously improve and contribute to enhanced patient safety.

\section{ACKNOWLEDGMENTS}

We thank all members of the Infection Control Program at the University of Geneva Hospitals, in particular Marie-Noelle Chraiti; Rosemary Sudan, for outstanding editorial assistance; members of the World Health Organization "Clean Care is Safer Care" core group: John Boyce, Barry Cookson, Nizam Damani, Don Goldmann, Elaine Larson, Ziad Memish, Hervé Richet, Manfred Rotter, Syed Sattar, Wing Ho Seto, Andreas Voss, and Andreas Widmer; and the Global Patient Safety Challenge team: Gerald Dziekan, Agnès Leotsakos, and Julie Storr.

Potential conflicts of interest. Both authors report no conflicts of interest relevant to this manuscript.

Address reprint requests to Didier Pittet, MD, MS, Director, Infection Control Program, University of Geneva Hospitals, 24 Rue Micheli-du-Crest, 1211 Geneva 14, Switzerland (didier.pittet@hcuge.ch).

\section{REFERENCES}

1. Raza MW, Kazi BM, Mustafa M, Gould FK. Developing countries have their own characteristic problem with infection control. $J$ Hosp Infect 2004; 57:294-299.

2. World Health Organization (WHO). The Global Patient Safety Challenge 2005-2006: clean care is safer care. Geneva, WHO, 2005. Available at: http://www.who.int/gpsc/resources/en/. Accessed June 11, 2007.

3. Blood supply and demand. Lancet 2005; 365:2151.

4. Mayon-White RT, Ducel G, Kereseselidze T, Tikomirov E. An international survey of the prevalence of hospital-acquired infection. I Hosp Infect 1988; 11:43-48.

5. Ponce-de-Léon $S$. The needs of developing countries and the resources required. J Hosp Infect 1991; 18(suppl A):376-381.

6. Western KA, St John R, Shearer LA. Hospital infection control and international perspectives. Infect Control 1982; 3: 453-455.

7. Macias AE, Muñoz JM, Bruckner DA, et al. Parenteral infusion contamination in a multi-institutional survey in Mexico: considerations for nosocomial mortality. Am J Infect Control 1999; 27:285-290.

8. Rezende EM, Couto BR, Starling CE, Modena CM. Prevalence of nosocomial infections in general hospitals in Belo Horizonte. Infect Control Hosp Epidemiol 1998; 19:872-876.

9. Rosenthal VD, Maki DG, Salomao R, et al. Device-associated nosocomial infections in 55 intensive care units of 8 developing countries. Ann Intern Med 2006; 145:582-592.

10. Zaidi AKM, Huskins WC, Thaver D, Bhutta ZA, Abbas Z, Goldmann DA. Hospital-acquired neonatal infections in developing countries. Lancet 2005; 365:1175-1188.

11. Kotisso B, Aseffa A. Surgical wound infection in a teaching hospital in Ethiopia. East Afr Med J 1998; 75:402-405.

12. World Health Organization (WHO). The World Health Report 2006: working together for health. Geneva: WHO; 2005. Available at: http:// www.who.int/whr/2006/en/. Accessed June 11, 2007.

13. Rosenthal VD, Maki DG. Prospective study of the impact of open and closed infusion systems on rates of central venous catheter-associated bacteremia. Am I Infect Control 2004; 32:135-141.

14. Lobo RD, Levin AS, Gomes LM, et al. Impact of an educational program and policy changes on decreasing catheter-associated bloodstream infections in a medical intensive care unit in Brazil. Am J Infect Control 2005; 33:83-87.

15. Rosenthal VD, Guzman S, Safdar N. Reduction in nosocomial infection with improved hand hygiene in intensive care units of a tertiary care hospital in Argentina. Am J Infect Control 2005; 33:392-397. 
16. Higuera F, Rosenthal VD, Duarte P, Ruiz J, Franco G, Safdar N. The effect of process control on the incidence of central venous catheterassociated bloodstream infections and mortality in intensive care units in Mexico. Crit Care Med 2005; 33:2022-2027.

17. Kurlat I, Corral G, Oliveira F, Farinella G, Alvarez E. Infection control strategies in a neonatal intensive care unit in Argentina. J Hosp Infect 1998; 40:149-154.

18. Berg DE, Hershow RC, Ramirez CA, Weinstein RA. Control of nosocomial infections in an intensive care unit in Guatemala City. Clin Infect Dis 1995; 21:588-593.

19. Pittet D, Donaldson L. Clean care is safer care: the first Global Challenge of the World Health Organization World Alliance for Patient Safety. Infect Control Hosp Epidemiol 2005; 26:891-894.

20. Pittet D, Mourouga P, Perneger TV. Compliance with handwashing in a teaching hospital. Ann Int Med 1999;130:126-130.

21. Pittet D, Boyce JM. Hand hygiene and patient care: pursuing the Semmelweis legacy. Lancet Infect Dis 2001; 1:9-20.

22. World Health Organization (WHO). WHO Guidelines for Hand Hygiene in Health Care (Advanced Draft). Geneva: WHO; 2006. Available at: http://www.who.int/patientsafety/information_centre/ghhad_download/ en/index.html. Accessed June 11, 2007.
23. Sax H, Allegranzi B, Uckay I, Larson E, Boyce J, Pittet D. "My five moments for hand hygiene": a user-centred design approach to understand, train, monitor and report hand hygiene. I Hosp Infect 2007; 67: 9-21.

24. Pittet D, Hugonnet S, Harbarth S, et al. Effectiveness of a hospital-wide programme to improve compliance with hand hygiene. Lancet 2000; 356:1307-1312.

25. Johnson PD, Martin R, Burrell LJ, et al. Efficacy of an alcohol/chlorhexidine hand hygiene program in a hospital with high rates of nosocomial methicillin-resistant Staphylococcus aureus (MRSA) infection. Med J Aust 2005; 183:509-514.

26. Pittet D, Sax H, Allegranzi B, Chraiti M-N, Richet H. Double-blind, randomized, cross-over trial of 3 hand rub formulations: fast-track evaluation of tolerability and acceptability. Infect Control Hosp Epidemiol 2007; 12:1344-1351 (in this issue).

27. Ahmed QA, Memish ZA, Allegranzi B, Pittet D. Hand hygiene and the Muslim healthcare worker. Lancet 2006; 367: 1025-1027.

28. World Health Organization (WHO). Pilot testing and evaluation of the GPSC and the WHO Guidelines on Hand Hygiene in Health Care (Advanced Draft). Available at: http://www.who.int/gpsc/country_work/ pilot_testing_info/en/index.html. Accessed July 30, 2007. 